\title{
A PÓS-GRADUAÇÃO EM ENFERMAGEM NO BRASIL SITUAÇÃO ATUAL
}

Maria Cecília Puntel de Almeida*

\begin{abstract}
O presente texto faz uma descrição da situação atual da pós-graduação em enfermagem no Brasil tendo por base os dados do biênio 90/91, da Coordenação de Aperfeiçoamento de Pessoal de Nível Superior - CAPES Referentes a: Corpo Docente, estrutura curricular, organização da pesquisa, produção científica docente, produção científico discente, tempo médio de titulação e fluxo de alunos. Finaliza com uma avaliação global da pós-graduação em enfermagem nestes 20 anos de existência.
\end{abstract}

\section{Introdução}

Neste primeiro número as Revista Latino-Americana de Enfermagem não poderíamos deixar de falar sobre a Pós-Graduação em Enfermagem no Brasil, pois tem sido esta a grande fonte da produção científica, e assim sendo, é ela que também vem delineando e conformando o conhecimento da enfermagem em consonância com as transformações do setor saúde na sociedade brasileira.

Não poderíamos deixar de apontar a pós-graduação e a pesquisa em enfermagem no Brasil frente ao alcance de divulgação deste periódico, que é a América Latina, afim de trocar experiências e intensificar o intercâmbio com os países latinos.

Os estudos pós-graduados "senso stricto" (mestrado e doutorado) foram instalados no país após a reforma universitária implantada a partir de 1968. Foram concebidos no país, para atender três motivos fundamentais: "01) formar professorado competente que possa atender à expressão quantitativa do ensino superior garantindo, ao mesmo tempo, a elevação dos atuais níveis de qualidade; 02) estimular o desenvolvimento da pesquisa científica por meio de preparação adequada de pesquisadores; 03) assegurar o treinamento eficaz de técnicos e trabalhadores intelectuais do mais alto padrão para fazer face às necessidades do desenvolvimento nacional em todos os setores"**. "Ela não derivou de um processo espontâneo de crescimento da produção científica e do aperfeiçoamento da formação de seus quadros, mas de uma política deliberada do Estado. Ela obedecia a uma decisão explícita, por parte do governo militar recém-estabelecido, de disciplinar e orientar o ensino

\footnotetext{
* Enfermeira - Professora Associada do Departamento de Enfermagem Materno-Infantil e Saúde Pública da Escola de Enfermagem de Ribeirão Preto da Universidade de São Paulo - Brasil. Coordenadora da Área de Enfermagem Junto à CAPES - Biênio 91/92.

NOTA: Parte desta temática foi apresentada no Encontro Internacional de Pesquisa em Enfermagem - Escola de Enfermagem de São Paulo da Universidade de São Paulo, São Paulo, Out/1992 e Seminário de Avaliação dos 10 anos de Pós-Graduação em Enfermagem da Escola de Enfermagem Alfredo Pinto da UNI-RIO, Nov/1992.

** Parecer n. 977/65 - definição dos cursos de pós-graduação. Relator Newton Sucupira. Brasil - Conselho Federal de Educação.
} 
superior no País. Seu escopo é a modernização deste ensino nos quadros do projeto de desenvolvimento econômico então adotado" $* \star \star$.

O sistema educacional do país passa na atualidade por uma grave crise; esta perpassa todos os níveis. Ainda não alcançamos a universalização da educação básica; é alto o grau de analfabetismo, bem como, a evasão escolar nos primeiros anos e são poucos os que chegam ao nível superior.

Mesmo nesta profunda crise educacional, DURHAN E GUSSO ao fazerem uma reflexão sobre a pós-graduação no Brasil dizem que "este constitui o setor mais bem sucedido de todo o sistema e isto deve ser considerado como uma conquista a ser preservada". Continuando, expressam que "o êxito é um tanto surpreendente, especialmente quando se considera que resultou de um esforço iniciado a pouco mais de um quarto de século, num sistema universitário marcado por severas deficiências. Logrou-se estabelecer neste curto espaço de tempo, cursos de mestrado e doutorado de bom nível em praticamente todas as áreas do conhecimento. $\mathrm{E}$ nestes cursos se concentram quase toda a capacidade de pesquisa que se construiu no Brasil, e

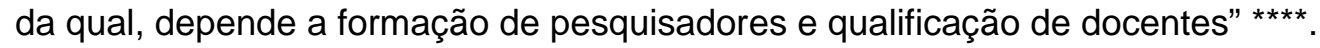

A pós-graduação conta (dados de 1989) com 1379 cursos, sendo 951 de mestrado e 428 de doutorado, com 46.504 alunos, sendo 36.382 de mestrado e 10.122 de doutorado e titulou em 1989, 6.037 alunos, sendo 5.040 mestres e 997 doutores. Enquanto o ensino superior se concentra nas instituições privadas com $61,5 \%$ das matrículas e $2 / 3$ dos egressos - a pósgraduação se encontra maciçamente em universidades públicas. De todos os alunos mestrandos do $1989,58,5 \%$ estavam nas federais, $27,5 \%$ nas estaduais e $14 \%$ nas particulares ${ }^{\star \star \star \star \star}$.

\section{Situação atual da pós-graduação em enfermagem}

A organização e o desenvolvimento da pesquisa em enfermagem no Brasil são bastante recentes, e estão intimamente ligados à pós-graduação "sensu stricto".

Como ocorreu com toda a pós-graduação brasileira, esta não foi instalada após a pesquisa já estar institucionalizada nas universidades; se assim tivesse ocorrido, a pesquisa encaminharia automaticamente para o nível de pós-graduação e esta já estaria em pleno desenvolvimento. Primeiro a pós-graduação se instalou no bojo da reforma universitária nos últimos anos da década de 60 , em pleno regime autoritário. Assim sendo, falar no poder da pesquisa em enfermagem no Brasil tem-se que se passar, necessariamente, pela pós-graduação e aí, nos propomos a fazer uma descrição sobre como esta se encontra no momento atual e propiciar uma reflexão conjunta sobre se a estrutura desta atendem as nossas necessidades em saúde advindas das grandes desigualdades sociais instaladas no país, ou seja, do nosso modo brasileiro de andar a vida.

A pesquisa como um processo isolado vinculado ao pesquisador e sem uma infraestrutura para o seu desenvolvimento, tem poucas possibilidades de existir e de responder às necessidades dos homens. Ela tem que ser um processo de trabalho coletivo, e a pósgraduação vêm demonstrando esta possibilidade, se bem que ainda de forma incipiente. E perguntamos como a pós-graduação pode ser uma estrutura que possibilite o desenvolvimento da pesquisa e assim o avanço científico e tecnológico da prática de enfermagem? Como explicita Newton Sucupira no Parecer sobre definição dos cursos de pós-graduação, "que o desenvolvimento do saber e das técnicas aconselha".

\footnotetext{
*** DURHAN, E. R. \& GUSSO, D. A. Pós-Graduação no Brasil - Problemas e Perspectivas. CAPES, Brasília, 1991. p. 4. (Mimeografado)

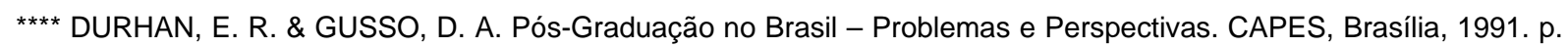
2. (Mimeografado)

***** Dados da CAPES, 1989.
} 
introduzir na universidade uma espécie de diversificação vertical com o escalonamento de níveis de estudos que vão desde o ciclo básico, a graduação até a pós-graduação. Haveria desta forma uma infra-estrutura correspondente ao plano de ensino, cujo objetivo seria, de um lado a instrução científica e humanista para servir de servir de base a qualquer ramo, e doutra parte, teria por fim a formação profissional; e uma superestrutura destinada à pesquisa, cuja meta seria o desenvolvimento da ciência e da cultura em geral, o treinamento de pesquisadores tecnólogos

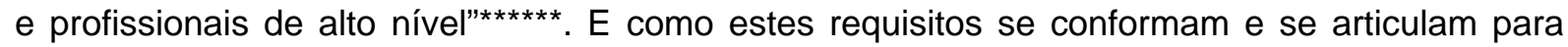
possibilitar o conhecimento científico? De forma genérica a pós-graduação se constitui e se expressa nos seguintes elementos: Corpo Docente; estrutura curricular; organização da pesquisa; produção científica docente; produção científica discente; tempo médio de titulação e fluxo de alunos.

Passamos agora a fazer uma descrição sumária e genérica da pós-graduação em enfermagem através dos itens apontados acima, tendo por base a última avaliação dos cursos realizados pela CAPES biênio 90/91, e pelo contato que tivemos com os cursos nestes últimos anos 91/92, enquanto Coordenadora da Área de Enfermagem junto a CAPES S $^{\star \star \star \star \star \star \star * ~}$

Corpo Docente - está constituído na sua maioria por enfermeiros, mas há ainda alguns cursos que para constituir seu Corpo permanente conta com a colaboração de outros profissionais da própria instituição de ensino superior e/ou de outras. Quando o curso tem uma natureza multidisciplinar é salutar a presença também de outras categorias profissionais. Quanto ao preparo do Corpo Docente observa-se que nem todos os cursos contam com a titulação de doutor de todos os seus docentes. A titulação dos docentes no nível de doutoramento vem se mostrando nos últimos anos uma necessidade de primeira ordem, para todas as regiões do país, com exceção do Estado de São Paulo que conta com a Universidade de São Paulo, que vem formando seus docentes no nível de doutoramento desde o ano de 1981, quando foi criado o primeiro doutorado no país. Atualmente a Universidade de São Paulo conta com três e em São Paulo há mais um na Escola Paulista de Medicina criado em 1989. Também o Estado do Rio de Janeiro conta com um doutorado na Escola de Enfermagem Anna Nery. Os docentes de outras regiões do país, nestes vinte anos de pós-graduação, em sua grande maioria, só fizeram a titulação no nível de mestre e demandaram muito pouco aos cursos de doutorado, que também são em pequeno número no país.

Esta pouca titulação dos professores enfermeiros é também o resultado do estímulo menor das universidades federais para a qualificação, bem como as dificuldades de descolamento de distantes regiões e as limitações sociais, ainda presentes, para a mulher dedica-se às atividades intelectuais. Em todos os 10 cursos de mestrados e 04 de doutorado (já avaliados pela CAPES), em 1990 e 1991 haviam, respectivamente, 221 e 207 professores permanentes, sendo 163 doutores em 1990 e 153 em 1991. Porém, esta distribuição por cursos é muito desigual; há cursos que contam com dois doutores enfermeiros e outros com mais de vinte a trinta doutores enfermeiros.

Verifica-se também, que para a própria manutenção dos cursos de mestrado e mesmo o desenvolvimento e atualização da graduação, faz-se necessário alcançar o nível de doutorado. É neste sentido que algumas propostas alternativas para suprir a formação de doutores vem se organizando no país como a extensão de Doutorado Interunidades da Universidade de São Paulo para Belo Horizonte na Escola de Enfermagem da Universidade Federal de Minas Gerais e a Rede de Pós-Graduação em Enfermagem para a Região Sul (REPENSUL), que esta estendendo o Mestrado da Universidade Federal da Santa Catarina para o Doutorado com participação de seis Universidades da região sul, e criação de outros mestrados na região. A região Nordeste conta só com dois mestrados: Universidade Federal da Bahia e Universidade

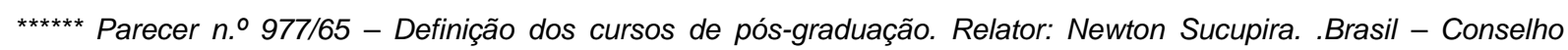
Federal de Educação.

****** Ainda a respeito da pós-graduação em enfermagem ver: ROCHA, S.M.M. et al O ensino de pós-graduação em enfermagem no Brasil. Cadernos de Enfermagem, 3., São Paulo, Cortez, 1989. P. 62
} 
Federal da Paraíba, e vem tentando pensar em organizar um doutorado. As Universidades Federais do Pará e Ceará já estão dando entrada de proposta de criação de mestrado junto a CAPES.

Outra questão que trouxe dificuldade para o Corpo Docente da pós-graduação foi a aposentadoria precoce de número considerável de docentes (devido a propostas de mudança na legislação da aposentadoria no país) com titulação e grande experiência em pós-graduação, fato este que desestruturou alguns cursos.

Quando à idade do Corpo Docente observa-se um envelhecimento do mesmo sem a entrada de jovens com titulação para comporem os quadros. A titulação de grande parte dos enfermeiros, tanto a nível de mestrado como doutorado, ainda se dá em idade considerada elevada, em torno dos 40 anos.

Estrutura Programática - esta deve manter uma coerência com a natureza do curso, ser suficiente para abranger a área de conhecimento e manter regularidade de oferecimento de disciplinas. Observa-se uma preocupação de quase todos os cursos em atualizar sua estrutura curricular, adequando-a à filosofia do curso. Ela também deve permitir flexibilidade ao aluno dentre um grupo de conteúdos da área de concentração e outro da área conexa. Quanto ao processo de aprendizagem deve permitir estimular a iniciativa criadora do aluno.

Atividades de Pesquisa - estas devem estar organizadas de forma a atender a natureza do curso e aos problemas de saúde e de enfermagem classificados como prioridade. As atividades de pesquisa expressam-se nas linhas e projetos de pesquisa. A investigação em enfermagem é ainda o resultado de pesquisas e projetos isolados. Não alcançamos a organização da pesquisa em linhas com projetos nas quais há a convergência de pesquisadores na formação de grupos.

Em alguns cursos, as linhas não correspondem à natureza da área de concentração e os projetos têm a participação de pesquisadores isolados.

A organização da pesquisa não se dá de forma mecânica e nem externa aos pesquisadores, ela vai se conformando no próprio processo de produção. Mas também não pode ser deixada a um processo puramente desordenado; precisa ir sendo analisada e organizada em linhas e grupos de pesquisadores no seu processo de desenvolvimento, sem tirar a característica de criatividade que é tão necessária neste processo.

Produção Científica Docente -como as atividades de pesquisa, pode-se concluir, estão na fase do processo de organização, sejam através de linhas e grupos de pesquisadores, a produção científica, que é o resultado destas atividades, ainda deixa a desejar. Em alguns cursos ela é quase ausente e em outros ela é considerável. A produção tem-se concentrado nos cursos da Universidade de São Paulo, Universidade Federal de Santa Catarina e Universidade Federal do Rio de Janeiro.

Em relação aos cursos, a área de enfermagem na CAPES ainda não analisa a qualidade desta produção. Isto tem sido objeto de estudo de alguns trabalhos que tem sido feito análises de teses e artigos publicados em periódicos. Torna-se limitada neste momento, a nível nacional, a análise qualitativa da produção docente da pós-graduação quando, uma parte considerável dos cursos conta com pouquíssima produção; portanto, a análise quantitativa, ainda, tem sido necessária. Os cursos de pós-graduação que estão com pouca produção científica docente precisam fazer um estudo buscando as causas desta situação: sejam internas aos cursos ou mesmo aquelas por falta de recursos financeiros e apoio logístico das entidades financiadoras de pesquisa e, montar estratégias para que ocorra a produção científica.

Observa-se em relação à natureza da produção científica que ela se concentra na produção técnica e artística e pouco nas publicações científicas como artigos em revistas indexadas, e menor ainda, em periódicos estrangeiros. Mesmo que a produção de enfermagem tenha muito haver com os problemas de saúde e da organização sanitária brasileira e, portanto, de grande interesse nacional, o intercâmbio internacional é necessário, muito salutar e positivo.

Produção Científica Discente - como as atividades de pesquisas ainda estão em fase de organização a produção seja isoladamente, seja junto a docente, ainda é incipiente na pós-graduação. Ela vem sendo estimulada nos últimos cinco anos e quando houver uma organização da pesquisa em linhas e projeto e grupos de pesquisadores, naturalmente, a produção discente começará a ocorrer, principalmente no nível doutorado que objetiva preparar pesquisadores.

Apresentamos a seguir alguns dados sobre a produção científica da pós-graduação. 


\section{PRODUÇÃO CIENTÍFICA E TÉCNICA DOCENTE E DISCENTE. SUB-ÁREA ENFERMAGEM, BIÊNIO 90/91}

\begin{tabular}{||l|c|c||}
\hline Natureza da Publicação & 1990 & $\underline{1991}$ \\
\hline Artigos Revistas Nacionais & 215 & 198 \\
\hline Artigos Revistas Internacionais & 05 & 10 \\
\hline Livros no País & 04 & 11 \\
\hline Capítulos Livros no País & 07 & 39 \\
\hline Capítulos Livros no Exterior & 01 & 02 \\
\hline $\begin{array}{l}\text { Trabalho Completo Congresso } \\
\text { Nacionais }\end{array}$ & 102 & 167 \\
\hline $\begin{array}{l}\text { Trabalho Completo Congresso } \\
\text { Internacionais }\end{array}$ & 01 & 16 \\
\hline Patentes e Protótipos & 03 & 00 \\
\hline
\end{tabular}

Fonte: CAPES/DAA

O quadro acima apresenta o total geral da produção dos cursos, mas o volume da produção se distribui de forma muito desigual em cada curso. Há vários cursos, por exemplo, que em relação aos artigos publicados em revistas nacionais em 1991 contribuem com o volume de 1 a 5 publicações e uma proporção menor com 30 a 40 artigos

Tempo médio de Titulação e Fluxo - este ainda é alto; o mestrado está em torno de 4 a 5 anos e o doutorado em 5 anos.

O fluxo é resultado de adequacidade e inter-relação de todos os itens anteriores, ou seja, quando a estrutura curricular é coerente com a área de concentração, com abrangência, regularidade e flexibilidade, quando o Corpo Docente é altamente qualificado para orientação em pesquisa, está engajado em linha e grupo de pesquisadores e as atividades de pesquisa estão organizadas, permitem um fluxo mais rápido com resultados melhores.

Corpo Discente - o número de alunos matriculados no mestrado nos anos 90 e 91 corresponde a 71 e 84 , respectivamente, e foram titulados também 71 e 72 nestes dois anos. No doutorado foram matriculados 32 e 23, e titulados 28 e 7 nestes mesmos dois anos. Esta distribuição também é desigual em cada curso. Estes dados estão no quadro abaixo.

CORPO DISCENTE. SUB-ÁREA ENFERMAGEM,
BIÊNIO 90/91
\begin{tabular}{||c|c|c|c|c||}
\hline \hline \multirow{2}{*}{ Situação dos alunos } & \multicolumn{2}{|c|}{1990} & \multicolumn{2}{c|}{1991} \\
\cline { 2 - 6 } & ME & DO & ME & DO \\
\hline Alunos novos matriculados & 71 & 32 & 84 & 23 \\
\hline Alunos em dezembro & 302 & 84 & 225 & 79 \\
\hline Titulados & 71 & 28 & 72 & 07 \\
\hline
\end{tabular}

Fonte: CAPES/DAA 
Fazendo-se uma análise global da pós-graduação em enfermagem instalada no país, que conta com vinte anos, podemos dividir os cursos no biênio 90/91 em três grupos: um grupo de cursos em progresso, outro em estabilidade e um terceiro grupo com queda de qualidade. Além destes já existentes, há outras universidades organizando suas pós-graduações.

Observa-se também uma concentração de cursos no Estados de São Paulo e Rio de Janeiro, dois no nordeste, um sul, e a inexistência nas regiões norte e centro-oeste do país. 0 nível de doutorado centra-se também São Paulo e Rio de Janeiro, cujas vagas ainda não dão vazão à demanda para outras regiões do país.

Uma política explícita institucional de qualificação do Corpo Docente, só começa a ser delineada nestes últimos anos. Até então, o deslocamento de docente de regiões desprovidas de pós-graduação para a cursarem em outras regiões ficava no plano individual.

Os enfermeiros não docentes estão começando a procurar a pós-graduação, mas também não há uma política institucional dos serviços para o desenvolvimento e aprimoramento de seus recursos humanos. Tem sido uma demanda espontânea a individual, sem liberação institucional para os estudos.

Nestes últimos dois anos, tem havido no país como um todo uma mobilização para criação de cursos, seja mestrado e doutorado e propostas alternativas como extensão de cursos a universidades que ainda não contam com a pós-graduação, união de esforços através de consórcios e/ou redes de pós-graduação para sanar a pouca mobilização destes últimos dez anos.

Não estou propondo aqui a abertura de cursos de pós-graduação indiscriminadamente, mas sim, somente onde haja condições infra-estruturais, como Corpo Docente qualificado, cursos de graduação e especialização com bom desempenho, uma produção científica em volume e qualidade suficientes, integração com os serviços de saúde e outras condições necessárias.

Há também a necessidade de fortalecimento de alguns cursos, principalmente, àqueles que vem apresentando uma queda na sua avaliação.

Após termos feitos uma análise de pós-graduação, que tem como um de seus objetivos a produção de conhecimento e de pesquisadores e se a pesquisa só tem razão de ser se estiver voltada para atender as necessidades dos homens, é preciso que este processo seja acompanhado e avaliado de perto, medindo-se a sua produção em função das respostas que tem dado à diversidade da situação de saúde do país, que convive com grandes desigualdades sociais: de um lado a concentração de renda em níveis elevados de uma pequena parcela da população, e de outra, o crescimento da pobreza, do emprego, o colapso do setor saúde, a alta mortalidade por violência, o extermínio de crianças abandonadas, as epidemias que estavam recrudescidas como dengue, cólera e outras.

A pós-graduação pode e deve contribuir para o desenvolvimento da pesquisa, mas se podemos contar só com alguns cursos, que no momento atual estão estruturados para esta contribuição, é necessária também a contribuição de todos os outros para atenderem às peculiaridades regionais e para tal, a enfermagem brasileira tem que estar voltada para a problemática de pós-graduação como um todo no país; procuramos fortalecê-la para que o processo de pesquisa se desenvolva e possa contribuir para as transformações da prática de enfermagem.

Assim sendo, tem sido muito importante a articulação da pós-graduação com a Associação Brasileira de Enfermagem, através de sua Comissão Permanente de Educação e seu Centro de Estudos e Pesquisa em Enfermagem - CEPEn para uma constante articulação e adequacidade da pesquisa com a prática de enfermagem.

Da mesma forma, outro órgão importante que vem contribuir para o desenvolvimento da pós-graduação de todas as áreas do conhecimento, no Brasil, é a CAPES, da qual passamos a fazer uma rápida explanação.

\section{Coordenação de Aperfeiçoamento de Pessoal de Nível Superior - CAPES}

Todos os cursos de pós-graduação do país são acompanhados por um órgão 
estatal/federal - CAPES. "” A Coordenação de Aperfeiçoamento de Pessoal de Nível Superior (CAPES) foi criada em 1951, no âmbito do ministério da Educação com o objetivo geral, como seu nome indica, de promover a formação de recursos humanos altamente qualificados, no nível de ensino superior, necessário ao desenvolvimento científico, econômico e cultural do País. Em virtude deste objetivo, sua área de atuação concentrou-se no aperfeiçoamento da qualificação dos docentes para a melhoria da formação oferecida aos alunos dos estabelecimentos de ensino superior. Especial atenção vem sendo formar docentes-pesquisadores, assim com, pessoal altamente qualificado para organismos públicos e privados. Assim, sua atuação se faz através de bolsas e fomentos e uma atividade de desempenho". (Plano de Ação da CAPES, 1991 - mimeografado).

Em 19 de maio de 1992, Decreto n. ${ }^{0}$ 524, a CAPES foi instituída como Fundação Pública (Diário Oficial ANO CXXX - n. ${ }^{\circ}$ 95, quarta-feira, 20 de maio de 1992).

A Estrutura Básica é composta por:

I Órgãos colegiados:

a) Conselho Superior

b) Diretoria

c) Conselho Técnico-Científico

II Órgão de assistência direta e imediata do Presidente:

a) Gabinete

III Órgãos seccionais:

a) Procuradoria Jurídica

b) Diretoria da Administração

IV Órgãos singulares:

a) Diretoria de Programas

b) Diretoria de Avaliação

O Conselho Técnico-Científico tem a seguinte composição:

- Presidente da CAPES que exerce a Presidência do Colegiado

- Os Diretores da CAPES

- Os Coordenadores das Comissões de Consultores Científicos da CAPES

Os Coordenadores das Comissões de Consultores Científicos são designados pelo Conselho Superior, entre profissionais de reconhecida competência, atuantes no ensino de pósgraduação e na pesquisa e têm mandato de dois anos, admitida uma recondução. Estes são, atualmente, em números de 26 , representado diferentes áreas de conhecimento. Nestas 26 áreas agrupam-se cinco grandes áreas que são:

01) Humanas e Sociais

02) Ciências da Vida

03) Engenharia e Tecnologia

04) Ciências da Saúde

05) Exatas e da Terra

A Área de Ciências da Vida é composta por Medicina, Nutrição, Enfermagem, Odontologia e Educação Física.

A Área de Enfermagem (que até então não havido sido contemplada pelo CTC) foi instituída pela Resolução n. ${ }^{\circ}$ 01/87, 7 de abril de 1987 - Foi Presidente da Áreas nos dois biênios anteriores 87/88 e $89 / 90$ a Prof. $^{a}$ Terezinha Teixeira Vieira, da Escola de Enfermagem da Universidade Federal da Bahia.

Este Conselho tem as seguintes competências:

I - assistir à Diretoria nas políticas e diretrizes específicas de atuação da CAPES;

II - colaborar na elaboração da proposta do Plano Nacional de Pós-Graduação;

III - opinar sobre a programação anual da CAPES;

IV - opinar sobre critérios e procedimentos para a distribuição de bolsas e auxílios institucionais e individuais;

V - opinar sobre acordo de cooperação entre a CAPES e instituições nacionais, 
estrangeiras ou internacionais;

VI - propor os critérios e procedimentos para o acompanhamento e a avaliação da pósgraduação e dos programas executados pela CAPES;

VII - propor a realização de estudos e programas para o aprimoramento das atividades da CAPES;

VIII - opinar sobre assuntos que Ihe sejam submetidos pelo Presidente no Conselho Superior;

IX - eleger seu representante no Conselho Superior.

\section{Conclusão}

Finalizando, gostaríamos de apontar para reflexão, a questão da avaliação do desenvolvimento dos cursos da área de enfermagem. A avaliação tem sido feita tanto pelos próprios cursos, que é a auto-avaliação e a externa que é realizada pelos próprios pares da área do conhecimento e é de responsabilidade da CAPES. Ainda, ela é uma avaliação quantitativa que vem buscando o seu aprimoramento para que seja também qualitativa. Este processo avaliativo tem finalidade educativa apontando as mudanças necessárias na estrutura organizacional dos cursos.

A auto-avaliação é sempre muito importante, pois motiva os docentes e discentes a participarem efetivamente, buscado mudanças e aprimoramentos. Ao mesmo tempo, a avaliação externa é necessária, pois permite à área não se distanciar dos parâmetros comuns a todos as áreas do conhecimento são estabelecidos pelas próprias áreas. Este processo está ainda em construção e vem sendo aprimorado a cada dois anos. E é importante que esteja sempre sendo remodelado para contemplar as transformações do conhecimento específico de cada área. $\mathrm{O}$ estabelecimento de critérios de avaliação da pós-graduação em enfermagem, e também de outras, não é um processo simples. Apontamos algumas dificuldades: primeiramente aquelas advindas das desigualdades da própria área; há cursos bem estruturados com boa produção científica e outros que ainda não alcançaram estes padrões. A outra dificuldade refere-se ao confronto de áreas entre aquelas consideradas "big science", e outras ainda em constituição, como a área de enfermagem. Mesmo sendo os critérios estabelecidos pelas próprias áreas, as demandas de enfermagem para bolsa no exterior, pós-doutorado e outros fomentos são ainda diminutos, que, de certa forma, dificulta o seu fortalecimento nos órgãos financiadores.

Podemos concluir que nestes vinte anos de pós-graduação temos contribuído, em certa medida, para melhorar a prática de enfermagem no país, mas podemos também dizer que temos um vasto campo pela frente em direção aos preceitos de reforma sanitária brasileira para possibilitar a todos os cidadãos o acesso aos serviços de saúde de boa qualidade.

This article describes the actual of post-graduate programs in nursing in Brazil based on data for the biennium 90/91, from the Coordination of Post-Graduate Programs (CAPES) regarding: the faculty curricular structure, organization of research, scientific production by the faculty, scientific production by the students, mean time for receipt of degree, and student flux. A global evaluation of post-graduate programs in nursing throughout their 20 years of existence is presented.

El presente texto hace una descripción de la situación actual del Post Grado en Enfermería en Brasil fundamentándose en los dados del bienio 90/91, de la Coordinación de Personal de Nivel Superior - CAPES referentes a: Cuerpo Docente, estructura curricular, organización de la investigación, producción científica de los docentes, producción científica de los educandos, tiempo medio de titulación y flujo de alumnos. Finaliza con una avaluación global da post Grado en Enfermería en estés 20 años de existencia. 